\title{
Metilfenidato: medicamento gadget da contemporaneidade
}

Luiz Carlos Brant ${ }^{1}$

Tales Renato Ferreira Carvalho²

BRANT, L.C.; CARVALHO, T.R.F. Methylphenidate: medication as a "gadget" of contemporary life. Interface - Comunic., Saude, Educ., v.16, n.42, p.623-36, jul./set. 2012.

The aim of this paper was to present the main aspects of non-medical use of methylphenidate. In methodological terms, we carried out a literature search to achieve better interdisciplinary understanding of this controversial and multifaceted use. We found that contemporary use goes beyond the trio of disease, health and care, to include man's incessant striving to surmount his limits and live well in society. This turns this medicine into a fetish and brings users closer to their frailty. It can be seen that methylphenidate was first produced and that afterwards, there was an attempt to scientifically configure attention deficit hyperactivity disorder (ADHD), i.e. first the medicine was invented and then the disease. We conclude that methylphenidate is yet another gadget of contemporary life: a short-term quickly consumed object and a within-reach connectable and disconnectable partner. It becomes a device for ephemeral pleasures, while produced and marketed as a medicine.

Keywords: Methylphenidate. Pharmaceutical preparations. Gadget. Amphetamine.
O objetivo deste artigo consiste em apresentar os principais aspectos do uso não médico do metilfenidato. Em termos metodológicos, procedemos a uma pesquisa bibliográfica na busca por uma melhor compreensão interdisciplinar dessa utilização polêmica e multifacetada. Constatamos que o uso contemporâneo ultrapassa a tríade doença, saúde e cuidado. Compreende a busca incessante do homem em superar seus limites e viver bem em sociedade, o que torna esse medicamento um fetiche, aproximando o usuário de sua fragilidade. Percebe-se que, primeiramente, produziu-se o metilfenidato e, posteriormente, tentouse configurar cientificamente o transtorno do déficit de atenção e hiperatividade (TDAH), ou seja, inventou-se, primeiro, o remédio e, depois, a doença. Concluímos ser o metilfenidato mais um gadget da contemporaneidade. Um objeto de consumo curto e rápido, parceiro conectável e desconectável ao alcance das mãos, tornando-se dispositivo de prazeres efêmeros, fabricado e comercializado como medicamento.

Palavras-chave: Metilfenidato. Preparações farmacêuticas. Gadget. Anfetamina.
${ }^{1}$ Curso Gestão de Serviços de Saúde, Departamento de Enfermagem Aplicada, Escola de Enfermagem, Universidade Federal de Minas Gerais. Av. Alfredo Balena, 190 sala 510, Santa Efigênia. Belo Horizonte, MG, Brasil. 30.130-100.

brantluiz@enf.ufmg.br

${ }^{2}$ Faculdade de Filosofia Ciências e Letras do Alto São Francisco. 


\section{Introdução}

Na contemporaneidade, algumas substâncias psicotrópicas (psique-mente; topos-alteração), ao modificarem os modos de ser, de viver e de trabalhar, apenas secundariamente são utilizadas para minimização do sofrimento. O seu consumo atual, diferentemente do que observava Freud em "O malestar na civilização", vem constituindo uma estratégia de potencialização para aumento de produtividade diante das transformações ocorridas no modo de produção capitalista desde as três últimas décadas do século XX. A busca de reconhecimento social pelo sujeito tem se tornado um estímulo para prescrições farmacológicas legais, para o uso recreativo e instrumental - voltado para a produção. Este tipo de consumo atinge escalas crescentes e alarmantes, cada vez maiores no Brasil e no mundo, especialmente, de substâncias que elevariam a capacidade produtiva.

Este processo de reestruturação capitalista transforma radicalmente o mundo do trabalho (Sennett, 2000; Bauman, 1998), opera a transformação do sofrimento em adoecimento (Brant, 2004, 2001), e produz ideais hedonistas que estimulam o consumo desenfreado de mercadorias, imagens, espetáculos e sensações. Tudo isso instiga a experimentação da dimensão espaço-tempo calcada na flexibilidade e em velocidades descomunais que desvalorizam o passado e pressionam o sujeito a viver "o tudo já, aqui e agora" (Guattari, 2000; Harvey, 1993).

Neste contexto, anfetaminas, como o Metilfenidato, têm sido prescritas como medicamento para potencializar performances escolares e laborais. Elevados níveis de produtividade em curto prazo, com baixo custo e alta qualidade, são imperativos colocados pela ditadura do sucesso a qualquer custo.

Apresentar-se sempre feliz e com disposição exuberante para atuar são dimensões atuais da cultura do narcisismo (Lasch, 1979) e da sociedade do espetáculo (Debord, 1992). A consequência imediata é o tamponamento da reflexão acerca da experiência cotidiana por meio da imposição de imagens de um futuro paradisíaco e materialmente promissor.

A produção do ideal de ser protagonista em cenários de sucesso está articulada ao discurso de que tudo depende, exclusivamente, da força de vontade do sujeito. Nas situações de dificuldades, desesperados por não corresponderem às elevadas expectativas, muitos são capturados por um outro discurso: a superação pode ser obtida por meio da aquisição de produtos de última geração. Esses produtos descartáveis são vendidos com a promessa de modularem desejos, elevarem a autoestima e proporcionarem a sensação de ganho de energia, constituindo verdadeiros gadgets. Evidenciamos que grande parte da prescrição e o consumo não terapêutico do metilfenidato, na contemporaneidade, o transformam em um autêntico gadget. Como tal, favorece ilusões ao usuário, alienando-o do árduo exercício de pensar em si mesmo. A frágil condição do sujeito na "Era pós-industrial", as neurociências, o setor produtivo farmacêutico e a mídia têm importante participação na criação deste gadget.

O presente artigo busca conhecer os principais aspectos da utilização do metilfenidato e os elementos envolvidos na indução do indivíduo ao uso não terapêutico, identificando os agenciamentos produção de subjetividades que engendram assujeitamentos e singularizações nesse tipo de consumo.

Em termos metodológicos, pesquisou-se a literatura especializada, nacional e internacional, por meio de livros, artigos científicos, dissertações de mestrado e teses de doutorado, buscando sempre uma apreensão interdisciplinar desse objeto complexo.

Nos limites de um artigo, traçamos uma condensada cartografia do uso indiscriminado do Metilfenidato como dispositivo - estratégia de assujeitamento utilizada pelo biopoder (Foucault, 1979) para aumentar a produtividade, particularmente na escola e no trabalho.

\section{Metilfenidato: elevação da produtividade}

O consumo contemporâneo de substâncias psicotrópicas difere das condições de uso dos últimos séculos. Até o início do século XIX, psicotrópicos associavam-se a práticas religiosas e outros aspectos da cultura, como lazer (Gurfinkel, 1995). O uso era regulado, basicamente, por controles sociais informais e autocontrole. O consumo de psicoativos ganhara uma nova e importante dimensão no pós-guerra. Com o neoliberalismo, a manutenção e o crescimento da produção industrial, a "psiquiatria deixa de ser um saber voltado exclusivamente ao tratamento da loucura para dedicar-se a medicar qualquer manifestação 
de sofrimento psíquico" (Gentil et al., 2007, p.314). Nessa sociedade, cada vez mais individualista, surge o discurso da medicalização que valoriza o estar sempre bem e o bom humor, pois o contrário pode configurar uma ameaça à inserção social e produtiva do indivíduo (Pelegrini, 2003).

A anfetamina surge em 1887, sintetizada pela, primeira vez, na Alemanha. Entretanto, quarenta anos após, foi usada pela medicina como: substância para "aliviar fadiga", descongestionante nasal, asma e estimulante do Sistema Nervoso Central (SNC). Em 1932, foi lançada na França com a derivação denominada Benzedrine, na forma de pó para inalação, e, mais tarde, como pílula. Durante a $2^{\mathrm{a}}$ Guerra, ela foi utilizada para "elevar o moral", "reforçar a resistência" e "eliminar a fadiga" de combate dos soldados. Tropas alemãs usavam a Methedrine e a força americana usava o Benzedrine. No Japão, os operários das fábricas de munição recebiam a substância para "eliminar a sonolência" e "embalar o espírito", formando um contingente com mais de quinhentos mil novos viciados (Sielski, 1999).

Pesquisadores observaram que a benzedrina (derivada da anfetamina) melhorava o comportamento das crianças agitadas, inquietas e desatentas. Apesar dos inúmeros efeitos colaterais, continuaram as pesquisas e descobriram, assim, o Metilfenidato, no início da década de 1940 (Fiocruz, 2009). Derivados anfetamínicos são estimulantes do SNC. Assim, em alguns casos, o Metilfenidato é utilizado com intenção de debelar o sono, deixar o sujeito "ligado" e "elétrico". Em outras situações, busca-se, com essa substância, melhorar o rendimento físico e intelectual. No âmbito do trabalho, é comum o consumo entre motoristas de caminhão, executivos e profissionais da saúde. Existe, ainda, o uso entre atletas e estudantes, sobretudo em véspera de provas (Fisberg, Medeiros, Carmo Filho, 2000, p.70). Todos esses casos caracterizam a existência de formas ilícitas de aquisição.

O metilfenidato foi sintetizado por Leandro Panizzon, farmacêutico da antiga empresa CIBA (atualmente, Novartis S/A) na Suíça, sendo patenteado em 1954. Foi comercializado, nesse mesmo ano e país, como um psicoestimulante leve. Já na Alemanha, não havia necessidade de prescrição médica para a compra. Chegou aos EUA em 1956, no Canadá em 1979 e, no Brasil, somente em 1998. O nome Ritalina se deve ao apelido da esposa do Dr. Panizzon. Marguerite se transformou em Rita e, depois, em Ritaline (Weber, 2000).

O uso não terapêutico do metilfenidato na atualidade se faz, em grande parte, por universitários, empresários e profissionais da área de saúde. Esses usuários, em geral, têm maior conhecimento sobre a droga em relação à população. Entretanto, trata-se de um público heterogêneo, com uma busca ativa de interesses diversos e subjetivos pela substância. Situação esta que remete a nossa investigação à condição de multifacetada, com variáveis incontroláveis e complexas.

O consumo não médico de metilfenidato é sui generis, por diferentes razões, entre elas, por se tratar de uma substância psicoativa com aspectos incomuns, comparando-se com o uso de outros psicotrópicos. Esse uso não se faz por simples curiosidade, como acontece com outras substâncias. Também não se deve a pura busca de prazer, euforia, mudanças na percepção de mundo ou sentimentos de bem-estar. Se, no passado, o psicotrópico constituía, essencialmente, estratégia para operar um transe entre dois mundos - o profano e o sagrado, na contemporaneidade, o metilfenidato parece estar associado ao aumento de produtividade (escolar e profissional), à crença de melhor sociabilidade ou de desempenho. Envolve elementos de ordem institucional, como saúde, educação, trabalho e economia. O consumo opera-se, sobretudo, mediante prescrição de um profissional do campo da saúde, em atendimento à demanda de um sujeito, individual ou coletivo, inserido nos setores da educação e/ou do trabalho, em resposta ao imperativo de uma economia em um mundo extremamente competitivo e globalizado.

O nosso maior desafio é circunscrever a especificidade do consumo do metilfenidato, uma vez que essa anfetamina situa-se em um contexto de alta complexidade. Barbosa (2008) sugere que a sociologia, antropologia, filosofia e psicanálise podem oferecer algumas contribuições para a sua compreensão, permitindo avanços conceituais nas relações entre homem, natureza e transformações culturais, ultrapassando, assim, as abordagens exclusivamente biológicas:

Se no início do século $X X$ a sociologia e a psicanálise, apresentavam pontos de convergência para refletir sobre o sofrimento psíquico, percebe-se que posteriormente, principalmente a partir dos anos 1950, essas duas disciplinas foram se distanciando, autorizando a Sociologia 
a deixar de oferecer uma contribuição significativa a essa temática, e permitindo à saúde mental tornar-se objeto quase que exclusivo do paradigma médico, ou mais objetivamente da Psiquiatria moderna, estabelecendo menos um diálogo e mais um conflito de abordagem. (Barbosa, 2008, p.98)

A utilização clínica de psicoativos tem crescido nas últimas décadas em países tanto do ocidente como do oriente. A elevação do consumo é atribuída: ao aumento de diagnósticos de transtornos psiquiátricos, à introdução de novos psicofármacos no mercado e às novas indicações terapêuticas de fármacos já existentes (Rodrigues, Fachini, Lima, 2006, p.108).

O uso não terapêutico do metilfenidato é raramente abordado em investigações científicas, como se não existisse ou não fizesse parte da realidade dos indivíduos. Ferreira et al. (2010); Scivioletto e Morihisa (2001) apontam que há um consenso: o uso e o abuso de psicotrópicos têm causas multifatoriais (biopsicossociais), envolvendo dimensões como curiosidade, obtenção de prazer, influência do grupo, pressão social, isolamento, baixa autoestima e dinâmica familiar. O "uso abusivo de drogas", além da dependência, ultrapassa o nível da clínica individual e configura-se como importante problema de saúde pública. Entretanto, a capacidade de o metilfenidato provocar dependência é controversa. Estudos interdisciplinares mostram a existência de grande diversidade de práticas discursivas evidenciando vários interesses acerca da utilização desse fármaco.

Para Fiore (2002, p.19), o prazer resultante do uso de "drogas" portaria, em si, uma negatividade decorrente da condição antinatural ou anormal. O uso seria plenamente dispensável, entretanto, o seu consumo pode ser considerado parte de uma "cultura universal". No caso do metilfenidato, o uso "não médico" vem sendo omitido e negligenciado em detrimento de interesses maquiados pelo discurso médico baseado nas neurociências. Admite-se, assim, apenas o uso terapêutico como justificativa única para comercialização do metilfenidato, conferindo, ao domínio médico, poder exclusivo sobre a sua legitimação.

\section{Metilfenidato: passado e presente}

Os primeiros usuários de benzedrina, derivação pioneira da anfetamina, descobriram que ela produzia efeito eufórico quando inalada. Tal acontecimento levou a substância à condição de primeiro estimulante sintético amplamente empregado para uso recreativo.

A Benzedrina foi a primeira droga sintetizada desse grupo, ainda no século passado e passou a ser utilizada clinicamente em 1932, para alívio de congestão nasal e asma. A partir de 1937, ela começou a ser utilizada para várias patologias neuropsiquiátricas, como narcolepsia, depressão, parkinsonismo pós-encefalítico e transtornos hipercinéticos. Desde essa época, várias outras drogas desse grupo foram sintetizadas e, ao longo do tempo, foi aumentando o seu uso lícito e ilícito. A partir dos anos 70, vários fatores regulatórios começaram a inibir seu uso clínico, estando ele, hoje, sujeito a poucas indicações. (Fisberg, Medeiros, Carmo Filho, 2000, p.766)

Para Itaborahy (2009), o metilfenidato, também um derivado anfetamínico, foi utilizado nos anos 1950 para tratar fadiga crônica e narcolepsia, não estando, inicialmente, relacionado a diagnósticos psiquiátricos. Entretanto, já era empregado para emagrecimento, melhoria da performance atlética e como automedicação para melhorar o desempenho intelectual.

Dr. Panizzon, fazia muitas experiências pessoais com esta substância, o que não o impressionava muito. Era, contudo, sua esposa que utilizava com freqüência a Ritalina, pois ela que sempre teve uma pressão arterial muito baixa aproveitava de sua ação tonificante e estimulante. Ela costumava tomar um comprimido de Ritalina antes de uma partida de tênis. (Itaborahy, 2009, p.62) 
Metilfenidato é o princípio ativo atualmente encontrado em medicamentos de referência - Ritalina ${ }^{\circledR}$ e Concerta ${ }^{\circledR}$ - disponibilizados no mercado farmacêutico, mas ainda não comercializado como similar ou genérico até o presente momento. Entende-se como aplicação terapêutica do metilfenidato: a sua propriedade de diminuir a inquietação motora, o aumento de concentração, atenção e memória (BPR, 2010). Na narcolepsia, ele produz: estimulação do SNC, aumento da vigília, diminuição da sensação de fadiga e elevação do estado de ânimo, entendido como alegria e ligeira euforia (P.R. Vade - Mécum, 2008; ITM, 2008). O seu principal emprego se faz no âmbito educacional, com o controle de crianças com Transtorno de Déficit de Atenção com ou sem Hiperatividade - TDA/H (Korolkovas, 2006).

Quando o metilfenidato foi descoberto, "não havia um diagnóstico específico para seu uso. Era indicado para tratar a fadiga presente em vários quadros psiquiátricos, como também para minimizar o cansaço em idosos" (Ortega, 2010, p.245). Havia um ostensivo empenho para se descobrir uma aplicação terapêutica para esse fármaco que pudesse justificar sua aplicação medicinal em função da alteração fisiológica produzida. A indicação para transtornos hipercinéticos-dificuldades em manter a atenção, com ou sem hiperatividade - pareceu constituir uma justificativa "cientificamente convincente" para a sua aplicação.

As primeiras referências aos transtornos hipercinéticos na literatura médica apareceram no meio do século XIX. Entretanto, sua nomenclatura vem sofrendo alterações contínuas. Na década de 40, surgiu a designação "lesão cerebral mínima", que, já em 1962, foi modificada para "disfunção cerebral mínima", reconhecendo-se que as alterações características da síndrome relacionam-se mais a disfunções em vias nervosas do que propriamente a lesões nas mesmas. Os sistemas classificatórios modernos utilizados em psiquiatria, CID-10 e DSM-IV, apresentam mais similaridades do que diferenças nas diretrizes diagnósticas para o transtorno, embora utilizem nomenclaturas diferentes (transtorno de déficit de atenção/ hiperatividade no DSM-IV e transtornos hipercinéticos na CID-10). (Rohde et al., 2000, p.7)

$\mathrm{Na}$ atualidade, o valor do uso terapêutico do metilfenidato está fundamentado no diagnóstico de TDA/H. A ampliação da definição da doença e a confiabilidade nos sinais e sintomas clínicos não laboratoriais passaram a servir como referência para legitimar o diagnóstico (Singh, 2007; Dupanloup, 2004). Embora o surgimento desse diagnóstico não seja consensual, descrições do ano de 1902, do médico inglês George Still, e a síndrome da encefalite letárgica contêm elementos morais e políticos semelhantes aos da história do TDA/H que se confundem, inclusive, no que tange ao diagnóstico. Esses elementos, demonstrados e ocultados pela história, são evidentes e reveladores para um olhar crítico do diagnóstico de TDAH. Dessa forma, constituiu-se a base histórica do TDA/H com todas as suas polêmicas e controvérsias (Caliman, 2010).

Foram investigadas exaustivamente as razões pelas quais poderia haver a discrepância de épocas do lançamento do produto entre o mercado internacional e o nacional. Em nenhuma das fontes de pesquisa, obtivemos sucesso no levantamento das prováveis condições envolvidas para a existência dessa lacuna de tempo. O medicamento, com o princípio ativo metilfenidato, chegou ao Brasil apenas em 1998. Itaborahy (2009), em sua investigação, analisa as publicações científicas dos principais periódicos brasileiros (jornais e revistas), além das destinadas ao público em geral, por dez anos de comercialização do fármaco no Brasil (1998 - 2008). Em 2009, é veiculado o primeiro relatório do Sistema Nacional de Gerenciamento de Produtos Controlados - SNGPC, pela Agência Nacional de Vigilância Sanitária - Anvisa.

Nesse documento, a Anvisa aponta o metilfenidato como um dos cinco principais medicamentos que deverão receber os holofotes da investigação científica e discussão na atualidade, pois se trata de um fármaco com características intrínsecas de uso, passível de múltiplas controvérsias e interpretações acerca de sua real eficácia, e com grande difusão no Brasil. 


\section{Metilfenidato: gadget contemporâneo}

As autoridades sanitárias alegam que existem indícios de abuso e desvio de utilização para outras finalidades senão as terapêuticas. O medicamento vem sendo foco de vários estudos e questionamentos quanto ao seu uso massivo e efeitos secundários, pois sua utilização já ocorre entre empresários e estudantes, para fins de emagrecimento e uso recreacional, na forma triturada ou diluída em água para ser injetado (Anvisa, 2010).

Essa forma de uso exige uma abordagem própria do campo da drogadicção, com relação a esse abuso do metilfenidato como droga pesada, na forma intravenosa. Encontra-se, na literatura, que o consumo oral, apesar de bloquear $60 \%$ do transportador de dopamina, promove um perfil bastante diferente de bloqueio com relação ao intravenoso, o que fornece um suporte teórico à observação clínica de frequência rara do abuso em pacientes com TDA/H (Neto Filho, 2010; Louza Matos, 2007).

Salientamos que uma droga leve pode se tornar pesada (e vice-versa) dependendo da sua forma de sociabilização no âmbito da cultura e de seu uso na esfera individual, considerando as interações rizomáticas entre indivíduo e sociedade. Os efeitos de uma droga em decorrência do abuso são atravessados também pelo conjunto de ideias, imagens e percepções que se constroem socialmente sobre a substância química. Extratos de cactos peruanos ou do peiote, por exemplo, assumem dimensões e manifestações corpóreas completamente diferenciadas quando utilizados em rituais religiosos e quando consumidos recreativamente.

Na contemporaneidade, se estabelece um sistema de circulação horizontal em que a droga é classificada como proibida, ilícita; ou vertical, em que ela é considerada lícita. Nesse último caso, a droga é reconhecida como medicamente autorizada. Portanto, a diferença classificatória entre o remédio e o veneno não está associada somente à dose, mas, também, à legitimidade institucional, assumindo-o ou marginalizando-o. Antidepressivos (fluoxetina) vêm sendo utilizados para tratar de síndrome metabólica, e anfetaminas (femproporex) para debelar o sono, quando as aplicações dos fármacos são modificadas em função das intenções do usuário. O clonazepam era essencialmente prescrito, por otorrinos, para tratamento do acúfeno (zumbido), mas, atualmente, é amplamente empregado como ansiolítico por psiquiatras.

Quando uma droga psicoativa é legalmente condicionada como terapêutica, a medicina torna-se a instituição responsável pelo estabelecimento do uso "controlado". Os usuários de uma mesma substância são reconhecidos socialmente como doentes quando recebem uma prescrição médica, e são rotulados de dependentes químicos na utilização para outros fins, que não sejam para o tratamento de uma doença. Ambos constituem uma população cada vez maior, merecendo especial atenção da saúde pública. Isso não significa a necessidade de se atender à imposição de uma sociedade demandante de respostas em curto prazo, o que dificulta o cuidado de si e o uso dos prazeres (Foucault, 1984).

A sociedade atual aceita a doença, mas não admite o sofrimento, e transforma-o em adoecimento. A manifestação da tristeza ou da decepção são diagnosticadas como depressão e, como tais, medicalizadas (Brant, 2008). Nessa perspectiva, com um olhar crítico, o diretor e roteirista cinematográfico Fassbinder nos revela, em seu clássico O Desespero de Veronika Voss (1982), a existência de pessoas que, na busca de alívio para o próprio desespero, procuram tratamento médico em uma clínica e se tornam dependentes químicos em decorrência de interesses econômicos, da médica, proprietária da clínica, e do secretário de saúde do Estado. Para esses personagens do cineasta alemão, assim como para tantos outros na vida real, inicialmente, a medicalização e a internação constituem uma "saída" para os males da alma. Posteriormente, opera-se o processo de adoecimento atribuição gradativa da identidade de doente. Considerados portadores de um distúrbio mental, esses indivíduos são aprisionados entre quatro paredes, que podem ser tanto as físicas - como as de uma instituição de tratamento, ainda que seja um consultório - quanto as químicas - pelo uso de medicamentos, que também pode deixá-los recolhidos no próprio lar.

O metilfenidato - mesmo tendo sofrido modificações consideráveis em sua estrutura molecular, quando se buscou a diminuição dos efeitos indesejáveis - pode revelar-se altamente propenso à dependência. Nos casos de uso prolongado, o número de estudos acerca desse efeito é raro. Alguns autores, como Pastura e Mattos (2004, p.103), admitem que a "dependência medicamentosa do uso do 
metilfenidato é um risco mais teórico do que prático." Mesmo assim, ele é amplamente comercializado.

A Ritalina ficou conhecida nos últimos anos por sua associação ao TDAH. Entretanto, este estimulante é comercializado desde os anos 50 na Suíça, na Alemanha e nos EUA. Nesses países, sua indicação era para pessoas idosas, para diminuir a fadiga. Não havia nenhum diagnóstico específico para seu uso. Foi somente a partir de sua associação com o TDAH que suas vendas alavancaram e a Ritalina tornou-se o estimulante mais consumido no mundo. No Brasil, foram vendidas quase 1.150.000 caixas de metilfenidato somente em 2007. (Itaborahy, 2009, p.9)

O medicamento é descrito no Anexo I da Portaria 344/1998 da Secretaria de Vigilância Sanitária do Ministério da Saúde - SVS/MS, atualizada pela Resolução 18/2003 da ANVISA, como substância psicotrópica (entorpecente) de controle internacional, passível de notificação de receituário do tipo - $\mathrm{A}$, emitida em formulário de cor amarela. Cor que sinaliza como entorpecente "a substância que pode determinar dependência física ou psíquica relacionada, como tal, nas listas aprovadas pela Convenção Única sobre Entorpecentes" - que é reconhecida pelo Decreto de Lei ${ }^{\circ}$. 54.216/1964 que aprova a convenção, assinada em Nova York em 30 de março de 1961 (Decreto Legislativo n 05/1964). Resultado da Conferência de Plenipotenciários, convocada pelos Conselhos Econômico e Social da Organização das Nações Unidas para limitar o cultivo, produção, manufatura e uso de entorpecentes em nível adequado exigido pelas necessidades médicas e científicas.

O metilfenidato aparece na lista de substâncias psicotrópicas entorpecentes, complementares à convenção pelo Decreto Legislativo $n^{\circ}$. 90/1972, na relação II do art. 33. Portanto, qualquer tentativa discursiva de transferir o receituário do fármaco da notificação de cor amarela (como entorpecente) para o de cor azul (como somente psicotrópico não entorpecente), atenderia única e exclusivamente a interesses apenas comerciais.

Argumentos de que a substância não causaria dependência advêm de prerrogativas entendidas como apenas teóricas, devido à ausência de pesquisas clínicas. Admite-se que a dependência poderia ser "apenas psicológica", com diferentes graus de alterações comportamentais. Advogar sobre a nãodependência é fundamental para os que defendem um menor controle da substância, com a alegação de que o receituário da cor azul seria suficiente, dispensando o de cor amarela. Argumenta-se que prescrições com tais características dificultam o tratamento, amedrontam os pais dos pacientes, tornam o produto menos acessível e pouco aceitável, criando, assim, preconceitos sobre a terapêutica. Carlini et al. (2003) alegam que tal receituário seria, neste caso, marginalizado, e os portadores de TDA/H ficariam assim estigmatizados, aumentando a resistência ou a inibição do uso do medicamento na terapia.

A tese da dependência psicológica está centrada na lógica de o usuário acreditar não mais ser capaz de produzir sem o uso do medicamento, e que o aumento da capacidade produtiva seria resultado de processos neuroquímicos "turbinados" pela substância. Entretanto, defensores da inocuidade do metilfenidato quanto à incapacidade de provocar dependência, admitem, ainda, a existência de um potencial terapêutico de "antidependência", contrapondo-se à ideia do malefício. Ou seja, o metilfenidato não necessitaria da classificação entorpecente, pois, prova-se o contrário. Nessa lógica, atribuiu-se, com o argumento, uma nova característica ao medicamento: utilizado adequadamente, ele teria a capacidade de reduzir riscos de crianças com TDA/H desenvolverem, na fase adulta, outros tipos de dependência química.

É possível verificar, no próprio bulário da medicação, impedimentos e restrições à prescrição no uso terapêutico, tais como: contraindicações, precauções e advertências, para a administração do produto em pessoas com tendência ao suicídio, comportamento agressivo, dentre outras particularidades. Orienta-se, ainda, sobre o impedimento de se fazer uso de bebidas alcoólicas, e que a utilização do medicamento deve ser prescrita com cuidado em pacientes com histórico de abuso de álcool. Salientase que, caso o paciente esteja em uma dessas condições, o médico deve ser avisado, cabendo a ele decidir se o paciente pode começar ou continuar com a medicação. Assinala-se, também, que, na condição de estimulante, o metilfenidato não pode ser indicado para crianças submetidas a maus-tratos 
e/ou distúrbios psiquiátricos. Indica-se cautela com indivíduos emocionalmente instáveis, como aqueles com história de dependência de drogas ou alcoolismo, pois eles podem aumentar a dose por iniciativa própria (Ritalina ${ }^{\circledR}$, 2011). Dessa forma, tais recomendações constituem uma variável importante, que seleciona indiscutivelmente o público a ser tratado com a medicação. Recebem ou mantêm o tratamento farmacológico apenas aqueles indivíduos que não são propensos à utilização de outras substâncias químicas de uso abusivo.

Para Biederman et al. (1999), 85\% dos portadores de TDAH tratados com o metilfenidato não fazem uso de outras drogas e de álcool ao longo da vida, concluindo, assim, que o metilfenidato diminui o risco e a incidência de drogadições. Fato que induz Carlini et al. (2003) a também atribuírem, ao medicamento, propriedade de antidependência. Essas e outras discursividades agregadoras de valores contribuem para confirmar a nossa hipótese: o metilfenidato constitui, na contemporaneidade, um gadget.

O enquadramento deste medicamento como entorpecente implica um rígido controle da substância pelos órgãos sanitários. Ainda assim, o metilfenidato é o psicoestimulante sintético "mais consumido no mundo, superando todos os outros somados" (Itaborahy, 2009 p.8). Juntamente com outros derivados anfetamínicos, como metanfetamina (Ice ou Pervitin) e a metilenodioximetanfetamina (Ecstasy), implicam, atualmente, graves problemas de saúde pública, considerando que eles podem ocasionar violência e acidentes de trânsito.

No cenário internacional, Greely et al. (2008) investigaram 1.427 pesquisadores, na qualidade de sujeitos da pesquisa, com o objetivo de avaliar o desempenho profissional. Verificaram que $20 \%$ dos entrevistados declaram fazer uso de metilfenidato como estimulante para melhorar a concentração e focar a memória. De acordo com Ortega (2010), o considerável incremento dessa substância se faz em razão de sua expansão para outros fins que não apenas terapêuticos. O medicamento tem sido usado tanto para o tratamento de patologias da atenção como para melhoria de funções cognitivas em pessoas saudáveis. Constatamos que a literatura especializada tem abordado apenas o uso terapêutico, evidenciando a ausência de investigação da prescrição como um gadgete do uso recreacional. Referimos o metilfenidato como um gadget, entendendo-o como uma mercadoria, um bem de consumo para obtenção de gozo - mesclagem de prazer e dor - segundo a terminologia lacaniana.

Para Demoulin (2007), gadgeté um objeto criado pela indústria da tecnologia, produto do discurso da ciência e do capitalismo tardio. De posse de um gadget, o sujeito se depara com um produto que proporciona um ganho real menor do que fora prometido no ato de sua aquisição. Diante de um prazer efêmero, instantâneo, que o deixa com a percepção de ter obtido apenas algo pela metade, o indivíduo começa a buscar, numa sucessão interminável, outros meios na tentativa de encontrar o produto que lhe permita completar a parte faltante. Nessa busca compulsiva de novos objetos, o sujeito é capturado pelo seu próprio meio (estratégia). Isso o coloca também na posição de meio - metade de si e de instrumento facilmente manipulável nas mãos daqueles que vivem em busca de vantagens sobre o outro.

Nesta perspectiva, a modernidade não poderia ser denominada como tardia, conforme proposição de Giddens (2000), tão pouco alta ou baixa, mas como Modernidade do Meio, segundo nossas constatações. Na Modernidade do Meio, como temos sugerido, o indivíduo é apenas meio sujeito (diferente de sujeito dividido, segundo a psicanálise), tornando-se, ele próprio, um gadget.

Como tal, o sujeito é capturado pelo presente (tudo já, aqui e agora) - as noções de passado e de futuro são abolidas -, desloca-se apenas o objeto, fazendo predominar o valor de gozo sobre o valor de uso. Nessa perspectiva, as pessoas utilizam metilfenidato ou são utilizadas por aqueles que o comercializam? A droga ideal, potencializadora, é sempre um objeto falso, mas o sujeito ávido de gozo continua a buscá-la. Informações, orientações e alertas são importantes, mas não suficientes para este sujeito abrir mão do gozo. Intervenções de outra ordem (transdisciplinares?) são necessárias.

Ortega et al. (2010), ao realizarem um levantamento bibliográfico das publicações científicas sobre "Ritalina" no Brasil, nos últimos dez anos, constataram a inexistência de estudos tendo como objetivo exclusivo a abordagem do uso não médico. Afirmam serem notórias as preocupações de autores brasileiros em garantir uma imagem benéfica e em segurar o uso do medicamento. Alegam que uma discussão rigorosa sobre as consequências do abuso dessa anfetamina prejudicaria a sua aceitação pelos pacientes e familiares. Em seus achados, inúmeros artigos de produção internacional, por nós 
pesquisados, apresentam argumentos favoráveis ao uso da Ritalina, mostrando os "equívocos morais" da interdição do uso do medicamento para melhora do desempenho cognitivo. Nacionalmente, a aquisição deste medicamento para uso "não médico" se faz, essencialmente, pela internet - de forma irregular e clandestina.

"No Brasil, não existem estudos concluídos sobre o uso não médico" do medicamento (Itaborahy, 2009, p.55). Investigações dessa ordem são urgentes, uma vez que podem favorecer o "monitoramento pelas entidades fiscalizadoras e a educação sanitária bem como às entidades de saúde e profissionais para que cada um possa tomar as providências cabíveis" (Anvisa, 2010, p.11). Os variados discursos veiculados na mídia e através da própria ciência reforçam o uso dessa substância e contribuem para o avanço estratosférico de suas vendas, como demonstra o Relatório do SNGPC. Constatou-se que "há diferentes hábitos de consumo do produto em cada estado brasileiro. Situação que exige a adoção de medidas sanitárias diferentes, conforme a necessidade, visando diminuir o abuso destes medicamentos, do ponto de vista epidemiológico" (Anvisa, 2010, p.41).

\section{Metilfenidato: a busca de potencialização}

O uso de substâncias psicotrópicas ocupa as funções de minimização do sofrimento e de abertura para o gozo - mistura de prazer e dor. Para Freud (1930), a fonte do sofrimento tem origem no social, derivada de nossa inserção no processo civilizatório que, ao impor tantas renúncias de necessidades vitais, fere o homem naquilo que ele porta de mais humano. Para o neurologista vienense, o consumo de substâncias químicas consola o sujeito em situação de sofrimento e o insere num excitante jogo em que vida e morte se mesclam, deixando-o sobre o fio da navalha. O relacionamento com outros homens é apontado como a causa de maior sofrimento. O mal-estar na civilização é, portanto, o mal-estar dos laços sociais.

Isso nos instiga a pensar que o metilfenidato não cumpre a função de minimizar o sofrimento, mas de estabelecer articulações funcionais ou de servilidade no âmbito da sociedade do sucesso, colocando o usuário dessa anfetamina na posição de gozo do outro. Observamos que parte da problemática envolvida no uso não médico do metilfenidato estaria relacionada com o atual "mal-estar na civilização" - a potencialização que se busca no metilfenidato não é a do sujeito, mas do outro. Capturadas num ardil, erroneamente, as pessoas acreditam que buscam poder, sucesso e riqueza para si mesmas, não se dando conta de que toda a sua produção é destinada à sustentação desse Outro.

Na sociedade do consumo, medicamentos são oferecidos como mercadorias mágicas. Na tentativa de sustentar o ideal de uma vida livre de problemas, a indústria farmacêutica procura provar a inocuidade de seus produtos, seja omitindo efeitos colaterais e reações adversas, seja na culpabilização do sujeito nos casos de dependência química ou psíquica. O medicamento, gradativamente, torna-se indispensável para a vida. Assim, desejos, sonhos, projetos e paixões se materializam em mercadorias que podem ser compradas e consumidas (Lefèvre, 1991).

Estamos passando de uma sociedade disciplinar para uma sociedade de controle (Deleuze, 1992). Nessa travessia, qualquer grito ou gemido é traduzido como disfunção neuroquímica, e a cura está sempre em um determinado medicamento (Matos, 2009). O discurso da prescrição medicamentosa como solução imediata para a angústia relacionada ao desconhecimento próprio das travessias estendese não somente ao sofrimento, mas, também, à sobreposição de corpos e mentes para potencializar a produção.

Portanto, a busca ativa por esses medicamentos potencializadores e a dependência como resultado se configuram como um gadgetconstruído socialmente.

O laço social entre os seres humanos implica em um gadget, um objeto de consumo curto e rápido. Um parceiro conectável e desconectável ao alcance da mão. Na Psiquiatria, os objetos produzidos pelo saber da neurociência são os medicamentos que podem facilmente virar objetos de consumo quando a psiquiatria entra no discurso do capitalista. (Quinet, 1999, p.13) 
O medicamento como instrumento terapêutico transformado em mercadoria torna-se um gadget, algo que se acredita prolongar as capacidades humanas, passível de compra e venda. O metilfenidato é parte dessa sociedade "criadora de necessidades de consumo que devem incorporar os bens produzidos em escala crescente" (Sevalho, 2003, p.2).

A Modernidade do Meio pode ser definida pela valorização, essencialmente, da cultura da imagem, em que o instantâneo e a busca pela satisfação imediata e contínua dos desejos são valores predominantes. Nela, todos os meios para se alcançarem resultados favoráveis e imediatos tornam-se válidos. Entre eles, o abuso de substâncias químicas para melhorar o desempenho, configurando o que poderia ser chamado de estética neuronal. Dessa forma, psicotrópicos são utilizados como cosméticos, esteróides como anabolizantes no fisiculturismo, e anorexígenos, no culto ao corpo belo.

O corpo adquire relevância expressiva, reafirmando padrões de beleza que são idealizados e materializados através de cirurgias plásticas e tratamentos com "photoshops," quando fotografados. $\mathrm{Na}$ cultura da imagem, o sujeito torna-se expecta-dor de si mesmo, geralmente acompanhado de abusos que podem alterar seu corpo e mente.

Para Pelegrini (2003), psicofármacos são substâncias que modificam a existência do homem e sua presença no mundo. Há, portanto, no seu uso, para além de um propósito terapêutico, um intento hedonista, o abandono do sofrimento. Diferentemente, Santiago (2001 p.25) afirma que não se deve "pensar em nenhuma tentativa de conceituação da droga, pois que tal empreendimento induz à homogeneização da multiplicidade de efeitos de sentidos, produzidos pela droga na ficção". Não há um axioma ou teorema possível para a droga. Existe uma miscelânea, um amálgama de contemplação perante o objeto que resiste ao domínio do conhecer, "do insondável e inatingível mistério do efeito phármakon, que consiste na presença constante da fuga de sentido".

\section{Conclusão}

O consumo abusivo de medicamentos em geral, e de psicotrópicos particularmente, representa um grave problema de saúde pública, e parece agravar-se ainda mais quando não se leva em consideração a produção de subjetividades adictas no seio da Modernidade do Meio.

Concluímos que a dificuldade de realização do presente estudo se fez, em parte, pela complexidade das dimensões de ordem imaginária, maquínica, social e biológica implicadas entre sujeito e o uso de metilfenidato. Entretanto, consideramos que uma abordagem crítica e reflexiva, capaz de abarcar os anseios que perpassam o sujeito no encontro com o phármakon, foi dificultada também pelo viés do paradigma dominante da ciência e do modelo biomédico fortemente presentes na literatura especializada. Sobretudo, quando situações particulares são apresentadas como verdades absolutas e universais. No caso do nosso objeto de estudo, há uma conjugação de forças para não trazer à luz da ciência o fato de que é a partir da produção do metilfenidato que se cria uma patologia, o TDA/H. Ou seja, primeiro inventou-se o remédio, para, depois, se forjar a doença, na tentativa de se criar um imenso mercado consumidor.

O uso contemporâneo do metilfenidato está além da tríade doença, saúde e cuidado. Compreende a busca incessante do homem para superar seus limites e viver bem em sociedade, o que torna esse medicamento um gadget, um fetiche capaz de aproximar ainda mais o usuário de sua frágil condição do ser-aí-no-mundo. 


\section{Referências}

AGÊNCIA NACIONAL DE VIGILÂNCIA SANITÁRIA - ANVISA. Resultados de 2009. Brasília, 2010. p.1-51. Disponível em: <http://www.anvisa.gov.br/hotsite/sngpc/ relatorio_2009.pdf>. Acesso em: 24 fev. 2012.

BARBOSA, S.R.C. O discurso da ciência e as percepções de profissionais de saúde acerca da depressão no contexto das transformações sócio-ambientais e culturais contemporâneas. Teor. Pesqui. - Rev. Cienc. Soc., v.17, n.1, p.97-119, 2008.

BAUMAN, Z. A modernidade líquida. Rio de Janeiro: Jorge Zahar, 1998.

BIEDERMAN, J. et al. Pharmacotherapy of Attention: deficit/hyperactivity disorder reduces risk for substance use disorder. Am. Acad. Pediatr., v.104, n.2, p.20-5, 1999.

BPR. Guia de Remédios - edição 2010/2011.10. ed. São Paulo: Escala, 2010.

BRANT, L. Da tristeza à depressão: a transformação de um mal-estar em adoecimento no trabalho. Interface - Comunic., Saude Educ., v.12, n.26, p.667-76, 2008.

Sujeito e sofrimento entre os trabalhadores que ocupam cargo gerencial. 2001. Dissertação (Mestrado em Epidemiologia) - Universidade Federal de Minas Gerais, Belo Horizonte. 2001.

O processo de transformação do sofrimento em adoecimento na gestão do trabalho. Tese (Doutorado em Ciências da Saúde) - Escola Nacional de Saúde Pública, Fundação Oswaldo Cruz, Rio de Janeiro, 2004.

BRASIL. Congresso Nacional. Decreto Legislativo n. 90/1972. Aprova o texto da Convenção sobre Substâncias Psicotrópicas, assinada em 21 de fevereiro de 1971 pelo Brasil. Brasília, 1972.

Congresso Nacional. Decreto n. 54.216/1964. Promulga a Convenção Única sôbre Entorpecentes. Brasília, 1964.

. Ministério da Saúde. Agência Nacional de Vigilância Sanitária - ANVISA.

Resolução da Diretoria Colegiada - RDC n. 18/2003. Publica a atualização do Anexo I, Listas de Substâncias Entorpecentes, Psicotrópicas, Precursoras e Outras sob Controle Especial, da Portaria SVS/MS n. ${ }^{\circ}$ 344, de 12 de maio de 1998, republicada no Diário Oficial da União de $1^{\circ}$ de fevereiro de 1999. Brasília, 2003.

Ministério da Saúde. Secretaria de Vigilância Sanitária - Portaria n. 344/1998. Aprova o Regulamento Técnico sobre substâncias e medicamentos sujeitos a controle especial. Brasília, 1998.

CALIMAN, L.V. Notas sobre a história oficial do transtorno do déficit de atenção/ hiperatividade (TDAH). Psicol. Cienc. Prof., v.30, n.1, p.45-61, 2010.

CARLINI, E.A. et al. Metilfenidato: influência da notificação de receita A (cor amarela) sobre a prática de prescrição por médicos brasileiros. Rev. Psiquiatr. Clin., v.30, n.1, p.11-20, 2003

DEBORD, G. La societé du spectacle. Paris: Gallimard, 1992.

DELEUZE, G. Post-scriptum: sobre as sociedades de controle. In Conversações. São Paulo: Editora 34, 1992. p.219-26. (Org.).

DEMOULIN, C. Gadget et hontologie. In: ASSOCIATION ACTE-PSYCHANALYTIQUE, MEMBRE DE CONVERGENCIA, MOUVEMENT LACANIEN POUR LA PSYCHANALYSE FREUDIENNE, 2007, Toulouse. Annales... Toulouse: Acte, 2007. p.7.

DUPANLOUP, A. L'Hyperactivité infantile: analyse sociologique d'une controverse socio-médicale. 2004. Tese (Doutorado) - Université de Neuchâtel, Neuchâtel. 2004. 
FERREIRA, T.C.D. et al. Percepções e atitudes de professores de escolas públicas e privadas perante o tema drogas. Interface - Comunic., Saude, Educ., v.14, n.34, p.551-62, 2010.

FIORE, M. Algumas reflexões a respeito dos discursos médicos sobre uso de drogas. In: ENCONTRO ANUAL DA ANPOCS, 26., 2002, Caxambú. Anais... Caxambú, 2002. p.28. Disponível em: <http://www.neip.info/downloads/anpocs.pdf>. Acesso em: 24 fev. 2012.

FISBERG, M.; MEDEIROS, É.; CARMO FILHO, W.B. Artigo de revisão: estimulantes/ hipnóticos. Pediatr. Mod., v.36, n.11, p.766-70, 2000.

FOUCAULT, M. História da sexualidade: o uso dos prazeres. Rio de Janeiro: Graal, 1984.

Microfísica do poder. Rio de Janeiro: Graal, 1979.

FREUD, S. Malaise dans la civilisation. Paris: Press Universitaires de France, 1971.

FUNDAÇÃO OSWALDO CRUZ - FIOCRUZ. Escola Nacional de Saúde Pública. RADIS Comunicação em Saúde. Rio de Janeiro: Ediouro, 2009.

GENTIL, V. et al. Clomipramine-induced mood and perceived performance changes in selected normal individuals. J. Clin. Psychopharmacol., v.27, n.3, p.314-5, 2007.

GIDDENS, A. Mundo em descontrole: o que a globalização está fazendo de nós. Rio de Janeiro: Record, 2000.

GREELY, $\mathrm{H}$. et al. Towards responsible use of cognitive-enhancing drugs by the healthy. Nature, v.456, n.7223, p.702-5, 2008.

GUATTARI, F. As três ecologias. Campinas: Papirus, 2000.

GURFINKEL, D. A pulsão e seu objeto-droga: estudo psicanalítico sobre a toxicomania. Petrópolis: Vozes, 1995.

HARVEY, D. Condição pós-moderna: uma pesquisa sobre as origens da mudança social. 2.ed. São Paulo: Loyola, 1993.

ÍNDICE TERAPÊUTICO MÉDICO - ITM. ITM, 2008/2009. Petrópolis: EPUB, 2008.

ITABORAHY, C. A ritalina no Brasil: uma década de produção, divulgação e consumo. 2009. Dissertação (Mestrado) - Instituto de Medicina Social, Universidade do Estado do Rio de Janeiro, Rio de Janeiro. 2009.

KOROLKOVAS, A. Dicionário terapêutico Guanabara. 13.ed. Rio de Janeiro: Guanabara Koogan, 2006.

LASCH, C. The culture of narcissism. Nova York: Warner Barnes Books, 1979.

LEFÈVRE, F. O medicamento como mercadoria simbólica. São Paulo: Cortez, 1991.

LOUZA, M.R.; MATTOS, P. Questões atuais no tratamento farmacológico do TDAH em adultos com metilfenidato. J. Bras. Psiquiatr., v.56, n.1, p.53-6, 2007.

MATOS, S.S. A biologização do sujeito da contemporaneidade: biopoder, violência e morte. In: II CONGRESSO SUL-AMERICANO DE PSICANÁLISE SOBRE VIOLÊNCIA, CULPA E ATO: CAUSAS E EFEITOS SUBJETIVOS, 2., 2009, Fortaleza. Resumos... Fortaleza, 2009. 6p.

NETO FILHO, M.A.N. Controle farmacológico do transtorno do défict de atenção e hiperatividade pelo do uso de cloridrato de metilfenidato. UNINGÁ Ver., v.2, n.4, p.6-10, 2010 
O DESESPERO de Veronika Voss (Filme). Direção: Rainer Werner Fassbinder. Intérpretes: Rosel Zelch; Annemarie Düringer; Armin Mueller-Stahl; Hilmar Thate; Cornelia Froboess. Monique - Alemanha: Paramount / Silver Screen, 1981 (1982). 1DVD(104 min.), son., preto e branco, em Alemão com legendas em Português, Inglês e Espanhol.

ORTEGA, F. et al. A ritalina no Brasil: produções, discursos e práticas. Interface Comunic., Saude, Educ., v.14, n.34, p.499-512, 2010.

P.R. Vade-Mécum de medicamentos 2008/2009. 14. ed. São Paulo: Soriak, 2008.

PASTURA, G.; MATTOS, P. Efeitos colaterais do metilfenidato. Rev. Psiquiatr. Clin., v.31, n.2, p.100-4, 2004.

PELEGRINI, M.R.F. O abuso de medicamentos psicotrópicos na contemporaneidade.

Rev. Psicol., Cienc. Prof., v.21, n.3, p.38-43, 2003.

QUINET, A. A Ciência Psiquiátrica nos discursos da contemporaneidade. Associação Mineira de Psiquiatria - O Risco, v.10, n.8, p.12-4, 1999.

RITALINA ${ }^{\circledR}$. Bula. Responsável Técnico: Marco A. J. Siqueira. Taboão da Serra: Novartis Biociências, 2011. Bula de remédio.

RODRIGUES, M.A.P.; FACHINI, L.A.; LIMA, M.S. Modificações nos padrões de consumo de psicofármacos em localidade do Sul do Brasil. Rev. Saude Publica, v.40 n.1, p.107-14, 2006.

ROHDE, L.A. et al. Transtorno de déficit de atenção/hiperatividade. Rev. Bras. Psiquiatr., v.22, n.2, p.7-11, 2000

SANTIAGO, J. A droga do toxicômano: uma parceria cínica na era da ciência. Rio de Janeiro: Jorge Zahar, 2001.

SCIVIOLETTO, S.; MORIHISA, R. S. Conceitos básicos em dependência de álcool e outras drogas na adolescência. J. Bras. Depend. Quim., v.2, n.1, p.30-3, 2001.

SENNETT, R. A corrosão do caráter: conseqüências pessoais do trabalho no novo capitalismo. Rio de Janeiro: Record, 2000.

SEVALHO, G. O medicamento percebido como objeto híbrido: uma visão crítica do uso racional. In: ACURCIO, F.A. (Org.) Medicamentos e assistência farmacêutica. Belo Horizonte: COOPMED, 2003. p.1-8.

SIELSKI, F. Filhos que usam drogas: guia para os pais. Curitiba: Adrenalina, 1999.

SINGH, I. Not just naughty: 50 years of stimulant drug advertising. In: TONE, A.; WATKINS, E. (Orgs.). Medicating modern America: prescription drugs in history. New York: New York University Press, 2007. p.131-5.

WEBER, R. L'histoire de Ritalin. Un Workshop à Lucerne a fait voir ce classique sous un nouveau jour. Stimulants dans la psychiatrie de l'adulte (prof. Brigitte Woggon). 1999. Lucerne (Switzerland): Life Sci., n.2, p.8-9, 2000. Disponível em: <http:// www.hypsos.ch/Infos/viewtopic.php?f=6\&t=103>. Acesso em: 03 jul. 2012. 
BRANT, L.C.; CARVALHO, T.R.F. Metilfenidato: medicamento gadget de la contemporaneidad. Interface - Comunic., Saude, Educ., v.16, n.42, p.623-36, jul./set. 2012.

Este artículo presenta los principales aspectos del uso no médico del metilfenidato. En términos metodológicos, se hizo una investigación bibliográfica en busca de una mejor comprensión interdisciplinaria de esta utilización polémica y multifacética. El uso contemporáneo ultrapasa la tríada enfermedad, salud y cuidado. Comprende la búsqueda incesante del hombre en superar sus límites y vivir bien en sociedad, lo que transforma este medicamento en un fetiche. acercando al usuario a su fragilidad. Se nota que, primeramente se produjo el metilfenidato y posteriormente hubo un intento de configurarse científicamente el trastorno de déficit de atención e hiperactividad, o sea, se inventó primero el remedio y después la enfermedad. El metilfenidato es un gadget más de la contemporaneidad. Un objeto de consumo corto y rápido, un compañero conectable y desconectable al alcance de las manos, volviéndose un dispositivo de placeres efímeros, fabricado y comercializado como medicamento.

Palabras clave: Metilfenidato. Preparaciones farmacéuticas. Gadget. Anfetaminas. 